\title{
Dynamics of HR Practices in Disruptive and Innovative Business Models in an Emerging Economy
}

\author{
Bashir Aboaba Mojeed-Sanni
}

Asst. Professor, Business Division, Higher Colleges of Technology, UAE

\section{Hakeem Adeniyi Ajonbadi}

Asst. Professor, Business Division, Higher Colleges of Technology, UAE

Doi: 10.36941/ajis-2019-0005

\begin{abstract}
Ethical issues in recruitment/selection and training/development, protection of employees rights concerning fair and adequate compensation, employee engagement, Flexi-working, maternity and paternity pay, job security and compulsory holiday pay are the issues that continue to bug web and platform-based businesses in emerging economies. While there are elements of infusion of HR and technology in practice and application, the role and perception of contemporary HR practices and practitioners in steaming the effects of disruptive business models on the afore-mentioned HR issues and constructs are both foggy and fussy. This research paper, therefore, focuses on understanding the $H R$ practices of disruptive business models and the challenges of balancing between ethics/best practices in HR and organisational bottom-lines. The research exploits exploratory data from secondary sources and gathers primary evidence from major stakeholders in Nigeria emerging web and platformbased businesses, otherwise know as the 'gig economy'. The study focused, specifically, on Uber and Taxify which are the two prominent transport platform networks operations in Nigeria. Samples were drawn from a large population consisting of 22 D\&I business executives, 150 D\&l operators, 5 industry regulator executives, and 500 service users. Sequel to the data collection, the quantitative data were analysed using SPSS to derive descriptive and regression analysis. This study found that despite changes in the business models of these organisations, particularly the human resource unit, new HR management systems such as the human capital management software for recruitment had also taken a new shape which is more effective and less expensive to organisations. The protection of employees' rights seemed to have been a critical issue leading to ethical concerns. Also, as a result of the 'gig' nature of the industry, it is challenging for organisations to measure the basis for maternity and paternity pay. This research recommends the need for ensuring fairness to all employees, eradicating tribal, age, gender and income discrimination, ensuring that the role of technology does not encroach into the privacy and flexibility of employees but rather to enhance their skills, development and overall competence.
\end{abstract}

Keywords: Human resource management, recruitment, disruptive business models, ethics, bottom-lines, flexibility

\section{Introduction}

Today's era of globalisation portrays a business environment that continually revolves around several emerging changes which have either engendered promising opportunities or threats to businesses around the globe. There is palpability that business world is gradually turning into a 'gig' 
economy driven by technological advancement. A terrain where a connection is made possible between organisations, workers, and consumers via digital platforms; this has promulgated a business community that comprises individuals who prefer to work part-time, shorter periods, and become freelancers translating into a pandemonium across diverse HR issues in a variety of organisations (Harris, 2017). Although this recent development in the business arena triggers countless benefits both for the employer and the employee, there are also a few challenges that are accompanied by this recent movement. On the one hand, employees are very likely to becoming more flexible with their working patterns (some deciding it is better to work from home), have increased income (from working part-time and in more than one organization) and also having to take more time off work for relaxation purposes and personal development (McDonnell et al., 2019). On the other hand, employers mainly the HR departments are ecstatic following the presumption that they can be more focused on talent acquisition, reducing the cost of labour and operations, and also directing efforts towards employing the right persons at the right time and for a specific task.

The gig economy commonly referred to as an 'era of digital disruption' has formed the basis for various debates and is critically diagnosed to have erupted huge concerns for HR managers. According to Horney (2018:20), "the rapidly accelerating growth of the gig economy represents one of the most significant and all-encompassing challenges faced by human resources professionals." Similarly, with about 3.5 million individuals undertaking gig works in the United States (US) in 2015, there is a projection of about 8 million gig workers in 2020 (Sharpe, 2015). In the UK, as of 2016, the number of gigsters has moved up to about 1.6 million (Vercida, 2017).

Fundamentally, the big question which remains unanswered is whether HR professionals can exhibit adequate patterns of dexterity to pilot the limitless changes in processes, culture, curriculums, and protocols originally mapped out for full-time workers to a new generation of completing the jobs using a prescribed talent portfolio that is overtaken by the so-called 'gigsters' or contingent workers. The drive for a better working condition that instigates a superior work-life balance for the workforce, is expected to increase the concerns about the ability of an employee to have more control over how they work, which includes having to create a balance between work and home, being independent or having to choose between projects that are passion driven (Horney, 2018).

Furthermore, HR professionals are, now more than before, saddled with the additional responsibility of taking remodelled actions geared towards gaining access to pivotal talents and leveraging them to fill in critical gaps in core capabilities. Moreover, ethical issues in recruitment/selection and training/development, protection of employees rights concerning fair and adequate compensation, employee engagement, flexible-working, maternity and paternity pay, job security and compulsory holiday pay are the issues that continue to bug the gig economy. This paper, therefore, focuses on understanding the HR practices of disruptive business models and the challenges of balancing between ethics/best practices in HR and organisational bottom-lines.

\section{Literature Review}

\subsection{The Gig Economy and Changing Business Models}

As earlier stated, the gig economy backed by improvements in technology gave rise to some innovative business models. Various research works have consistently alluded that the gig economy though makes HR practices seems at ease, it does come with various complexities in workforce management. For one, according to Chander (2017) gig businesses are required to comply with the Employment Law of the countries they operate, which often states the rights of employees, workers and self-employed individuals. There are also responsibilities which these groups of individuals owe their employers if such employment rights are to be fulfilled (Chander, 2017). The differences in the workforce, that is, employees, workers and self-employed have been one of the critical challenges for organisations with a large workforce having to group them into one of these categories. Similarly, Horney (2018) alludes that the terminology 'employee' or 'employer' has become obscured, therefore necessitating for changes in business models to be able to deal with the complexities attached to the recruitment and working conditions of the workforce. 
It is noted that the gig economy erodes existing labour laws in some countries, such as the Wagner Act of 1935 and the Fair Labour Standards Act of 1938 (Horney, 2018). It was further implied that the increasing growth of the gig economy coupled with the supportive talent platforms had altered various business models; moreover, the definitions of the three main different categories of labour rests on their ability to control and influence their interests as against their employers. While 'employees' are acknowledged to have greater power and control over their employment rights, 'workers' are surmised to have little control or power regarding their rights and the 'self-employed' individuals have lesser or no control over employment rights (Bracha and Burke, 2018). Under these circumstances, there have been several campaigns and debates supporting changes in the business models of organisations and the basis for measuring the anticipated labour models to suit the flexibilities induced by activities in the gig economy.

As the number of "gigsters" increases, the need for HR professionals to implement innovative business models to stem the effects of changing activities and methods of doing business or carrying out specific tasks is paramount. According to Balaram, Warden and Wallace-Stephens (2017), the innovative models needed for the gig economy is somewhat complicated; however, both the government and employers are key decision makers regarding how to manage the gig economy. Notably, using algorithmic management (for instance, Uber), talent portfolio or ondemand talent model (such as the Japanese 'Just-in-Time' model), integrated user-defined mechanisms, and artificial intelligence will likely abate the current business turbulence. Similarly, Horney (2018) reveals that the new era created by the gig economy gives rise to volatility, uncertainty, complexity and ambiguity - VUCA; asserted that to develop the models needed to manage the gig economy, four critical factors to be assessed should include: the labour laws, the number of gigsters, leadership in the gig economy and the entire global workforce.

\subsection{Diversity and Ethical Concerns in Recruitment}

The complexities associated with the gig economy have agitated for the remodelling of some HR functions; one of these includes the basis for recruiting individuals with a different mindset or culture and managing such differences. According to the Deloitte Millennial Survey in 2018, diversity is a very critical aspect of recruitment and as such needs to be given ample considerations. The survey noted that although diversity in the workplace comes in various forms, however, the primary forms of diversity includes tolerance, inclusiveness and openness; respect and acknowledgement of the personality of the individual; and the differences in the way of thinking or ideas. Further reported was the implication of diversity on the gig economy taking into consideration factors such as age, gender, disability status, and ethnicity and more prominently is educational background. The nature of the gig economy which is seemingly driven by technological eruptions from time to time has necessitated for the professionals in HR management to build a strategy for not only engaging employees but also ensuring that fairness is at the centre of the decision-making processes, particularly during recruitment and promotion exercises.

According to Delgado (2018), it is evident that the gig economy gravitates towards creating an enabling platform for organisations and customers/consumers by creating a link to easily connect both parties without the need to either meet physically or improving access to connectivity. The role of the virtual workplace is beginning to improve organisational efficiency wherein business transactions can be carried out in the home or out of the office with the aid of a digital device that facilitates the entire or a significant part of the process. Delgado (2018) contrary to the position of Darwin and Palanisamy (2015) further implied that issues of diversity are unlikely to be a significant problem with employees working as freelancers or on contract because organisations have the choice to employ their services as at when needed. Therefore, introducing the just-in-time strategy into recruitment is beneficial to reducing labour and operational costs.

However, Darwin and Palanisamy (2015) revealed in their studies that diversity in the workplace is a critical issue for the HR department. As such, the need to manage diversity is a vital role of HRM; it alludes that diversity comes in various forms, which in most cases creates differentials in pay and compensation of employees or workers and a more critical aspect of HR, diversity has been observed to erode the rights of employees. Additionally, the role of HRM in 
ensuring fair pay and equal treatment has been accorded to be linked with organisational performance. Many business analysts and researchers have examined the effect of bias on employee performance at work and as such, topics surrounding gender pay discrimination, pay differentials by ethnicity and sexual orientation have been increasingly debated. Similarly, based on the observations, studies like Vercida (2018) opines that the gig economy is bound to be affected by management decisions on diversity; the structure put in place by many organisations although on paper advocates for fair play and equality but in reality the reverse is the case. The effect of the different forms of diversity on the gig economy is somewhat increasing the concerns of major stakeholders particularly the gigsters and as such, creating problems for HR professionals who seem lost in the thought of how to ensure equality and fair play among the categories of the workforce.

Also, many other business experts have viewed the educational status of the labour force and concluded that diversity problems will be at its peak in the gig economy because employers are beginning to tilt towards recruiting about $75 \%$ skill-talented workers who in many cases are attributed to the form and status of education that has been acquired by these individuals (Darwin and Palanisamy, 2015; Anita and Swamy, 2018). Talent portfolio-based selection is changing and remodelling HR functions and the need to curb unnecessary costs while improving productivity.

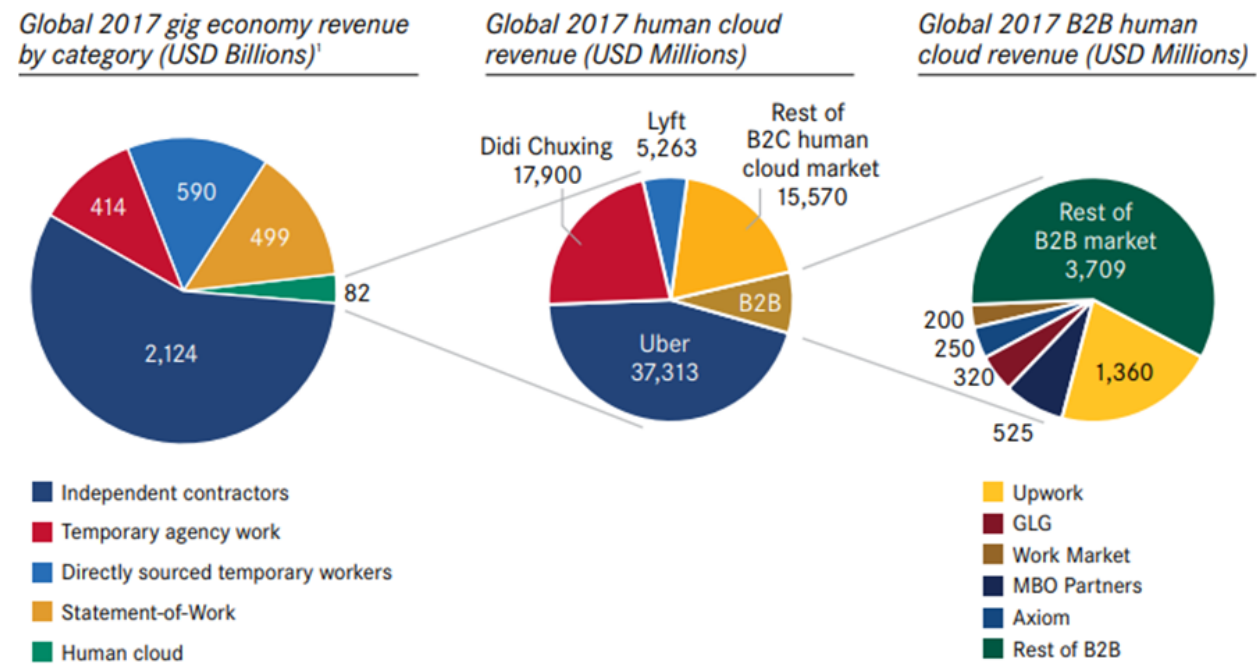

Source: Staffing Industry Analysts (2018)

In another dimension, diversity from outsourcing labour has been overly debated. With several investigations on the influence of cultural diversity on business performance, researchers have come to conclude that it is a very challenging aspect of HRM stemming from the fact that managing people from different cultural backgrounds often result in a clash of interests and divergence of purpose or objectives. According to Kshetri (2007 cited in Adekoya et al. 2018) the already prevalent organizational values and norms are affected when an external outsourcing vendor comes into the organization; thus, often leading to a divergence between the organization and the external vendor as they both have different cultural beliefs or ideals to achieve their respective goals. Recent findings report that in the gig economy of many developed countries like the US and UK, where there is a massive influx of migrants coupled with the high percentage of non-citizens in the labour force, there is more likely to be an occurrence of higher cultural diversities (Balaram et al., 2018).

Also, the ethical issues facing gig economy is a daunting challenge for HRM, and as such, the need for a critical assessment of an organisation's plan or strategy to mitigating such challenges 
cannot be downplayed. According to Vercida (2018), ethical defaults by organisations have cost many a fortune. One of the popular court cases relating to the gig economy remains that of Uber against its drivers in the UK. Uber is left with, having lost its appeal, the court's ruling which pronounced that its drivers should be regarded as workers and not self-employed, and as such, they are entitled to the rights as stated in the employment law such as paid holidays and eligibility for the minimum wage pay (Butler, 2018). According to the Staffing Industry Analysts report (2018), the major ethical concerns include bias in recruitment and selection, job security and protecting an employee's rights at work, employee engagement, and maternity and paternity pay to mention a few. In the studies of Ugargol and Patrick (2018), it was reported that employers in the gig economy tend to intrude into the privacy of their workers for the benefit of monitoring performance and efficiency; while some employees are less bothered, many others perceive it as an infringement of their right to privacy. For instance, Uber and Taxify drivers often get monitored via their smartphones using gyrometer and GPS data (Rao, 2016). Similarly, Horney (2016) observed that many organisations sometimes monitor workers emails and online activities to ensure that they are committed to the organisation and are in alignment with the goals and objectives of the organisation. Moreover, concerns regarding the payment of paternity and maternity leaves have been a recurring debate for HR professionals, and it seemingly tends to be inconclusive, a result of the dichotomy and fogginess in the classification of the labour force prevalent in the gig economy employees, workers and self-employed.

\section{3 'Flexicurity' in the Gig Economy}

Over the years, employees have always yearned for job flexibility with the aim of creating a worklife balance and also enabling them to rely on more than one source of income. According to a Gallup (2018), it was implied that while the younger workforce is experimenting in the gig economy out of necessity than choice, the older workforce has made working in the gig economy their preference. It is not farfetched to understand that the older workforce has the most intention to create a better work-life balance that enables them to juggle between work and other activities relating to their personal and family life; this has increased the number of older workers that prefer to work part-time, independently, or as freelancers. The controversy behind flexi-working has given rise to a massive campaign advocating shorter working hours, working from home, longer paid leaves, and the ability to hold multiple part-time jobs (Horney, 2018).

Similarly, with the new laws emerging in countries like the United Arab Emirates (UAE), wherein workers are granted permission from the Ministry of Human Resources and Emiratisation (MoHRE) to work part-time in multiple organizations without prior consent from their primary employer, will revolutionize the role of HRM in discharging some of its duties particularly employee retention (Khaleej Times, 2018). Regulations of this nature may prove difficult for HR professionals to handle; this is because, there is a risk of information sharing, meaning that part-time workers can directly or indirectly divulge information to competitors. Also, there is a risk of transcending from fulltime jobs to part-time jobs which, on the one hand, results in reduced cost of labour. However, may also give rise to business inefficiency which is relative to the type of job activities involved; this may have a longer effect on HR roles and strategies towards the recruitment of the right individual for the job (Ugargol and Patrick, 2018).

More specifically, the gig economy being an ardent advocate of flexi-working conditions further complicates issues for contemporary HRM. The principal question remains how HRM plans to remain fair and unbiased in its decisions towards engaging employees, dealing with bonuses/compensation, paid leaves and the rights of employees/workers. With the recent employment lawsuits against companies like Tesla, Apple, Asda, Samsung, Sony, Uber, Deliveroo and many others, organisations are beginning to reconsider their employment patterns and strategies, and the pressure has been on the HR departments of these organisations.

To buttress, the clamour of job security among employees/workers in the gig economy generates problems for HRM; moreover, employees tend to measure job security by the tenure of the job, employment rights, stable working conditions, and their physical and emotional wellbeing (Ajonbadi, 2016). According to Michelle and Helen (2016), the ability for organisations to constitute 
realistic plans for job security motivates employees to be more efficient and committed to their jobs; in reverse, when employees sense job insecurity, they tend to devise ways to be retained or look in advance for other job opportunities. The present nature of the gig economy does not assure employees of job securities because employers are uncertain about the commitments of many of their workers and as such, they fail in their responsibilities to provide their employees with some of the basic employment rights. Some employers opine that their part-time employees tend to be less committed relatively to their full-time employees; this is because, employees being human may tend to be more committed to some jobs than the others which makes it difficult for the HR department to build talents and incorporate the voice of employees in their organisational decision-making processes (Mordi, 2008).

Also as a result of work flexibility emanating from the ability to work for shorter hours, employees working with the direct competitors of the host organisation may be treated differently from the others who are committed to the organisation only or work in the unrelated industry. Practically, the HR strategy to improve employee involvement may be defeated as employers may find it difficult to expose critical plans to their employees as a means of protecting the interest of the organisation (Deloitte Millennial Survey, 2018).

\subsection{Nigeria: An Emerging Gig Economy}

As one of the countries under the African Continent, precisely West Africa, Nigeria has over the years proven to be 'The Giant of Africa' as it is commonly referred to by its strength and influence on the continent and the global village as a whole. Although the country depends primarily on its natural resources, oil, in particular, it has continued to show the potentials for growth through diversification.

Since the $21^{\text {st }}$ Century, the continuous improvement in technology has altered the patterns and processes for getting work done; and as such, the proliferation of technology around the world has impacted the rapid growth of the workforce leading to a rise in the gig economy. The gig economy predominantly known for its high dependence on technology and changing work models sets a standard for organisations in their mode of business operation. In the Nigerian context, technology has always revolved around many activities engaged in by the workforce; however, being an emerging gig economy, the nation is yet to sufficiently harness the benefits of improved technology (Nwanze, 2017). Before the introduction of a standard working time frame by the government, a significant number of Nigerian workers have always had to begin preparing for work as soon as the cock crowed and closed from work as the sun goes down. The rise of the gig economy being a fragment of capitalism has begun to change the working patterns of the average Nigerian citizen (Mojeed-Sanni and Adetunji, 2015).

The Nigerian business environment continues to forge ahead in its capacity to engage the use of technology and internet facilities to ensure continuation in business operations. The business environment has evolved from various innovations and with the advent of online shopping stores such as Konga, Jumia, Mystore, JiJi, and OLX; the rise in the number of bloggers and vloggers (online journalism/social media marketing); online financial businesses; and affiliate digital marketing to mention a few, the rise is on the increase.

Nigeria, like every other emerging gig economy, also reaps both the gains and consequences of the work changing models. Although working part-time and on shifts are beginning to increase predominantly in the supermarket business like Shoprite and restaurants like Sweet Sensations and Tasty Fried Chicken, Nigerian freelancing workers are also on a steady rise. The increase in freelance websites such as Asuqu, Gigs Nigeria, FindWorka, Justfrom5k, and SourceGig to name a few have eroded the Nigerian labour market and finding more preference for attracting the youth workforce. Moreover, the gig economy in Nigeria is beginning to advance into the broader society, and as such, there are teeming challenges faced by employers with the preference for full-time workers (Adeleke, 2017).

Additionally, unlike in many developed nations, employment rights are not entirely taken seriously in Nigeria. One of the reasons for this is the ignorance of the Nigerian labour force regarding their rights. However, for the few that are conversant with their rights and with the 
intervention of the labour unions, there have been several confrontations against the government and private employers particularly on matters relating to minimum wage and increase in wages/salaries. Other employment rights that help improve the work-life balance of workers have been ignored, wittingly or unwittingly. Nonetheless, Nigerian workers are beginning to crave for job flexibility and the need for organisations to be ethically responsible (Nwanze, 2017; World Economic Forum, 2018).

\subsection{The Case of Uber and Taxify}

Uber and Taxify are the prominent public transportation platform companies in Nigeria entering the Nigerian market in 2014 and 2016 respectively. Uber as at the last quarter of 2018 was able to boast of about 9000 drivers and 300,000 riders monthly (Vanguard, 2018). With over $\$ 15$ billion in equity and debt, the giant ride-sharing app company has continued to expand across continents. Dominant in Lagos and Abuja, Uber declared in 2016 that its Lagos market has more potentials than its London market (African Business Central, 2017). On the other end is Taxify representing Uber's biggest rival and operating in Lagos, Abuja, Ibadan and Owerri. The company currently acquires over $€ 2$ million in the last quarter of 2018 (Vanguard, 2018).

These transport platform companies have been one of Nigeria's biggest gigs working community based on their high dependence on technology and digitalisation. As a ride-sharing app organisation, the companies have been able to accommodate many freelancers into working as partner drivers for pay from which it deducts its commission. Given the flexibility the job offers in the business environment, the number of drivers has been increasing despite the challenges and threats to life that have been raised in recent happenings. For both companies, there have been a series of complaints from the drivers about the riders and vice versa. Also, particularly for Uber having had not less than three (3) recent lawsuits against its drivers, there have been quite some allegations against the transport companies on several counts. Besides, many of the drivers alleged that the companies have been unfair in their payment structure, ignored their rights as workers and are ethically irresponsible. These challenges and many others have become a big problem for HRM, and the need for remodelling and diffusing the inherent fogginess in the employer-employee relationships in these sort of organisations is contingent for harnessing the benefits inherent in gig economies and tackling any HR issues that might arise in the future.

\section{Methods}

Relying on interpretivist philosophy that considers the human nature of research and recognises the difference between people and the objectivity of natural sciences which necessitates that social scientists need to understand the subjective meaning of social actions. The research exploits exploratory data from secondary sources and gathers primary evidence from major stakeholders in Nigeria emerging gig economy with specific attention Uber and Taxify which are the two prominent transport platform networks operating currently in the country of study - Nigeria. In collecting primary data, the stakeholders were grouped into primary (D\&I business executives and operators) and secondary (Industry regulators' executives and service users) participants. Samples were drawn from a large population consisting of twenty-two (22) D\&I business executives, one hundred and fifty (150) D\&I operators/drivers, five (5) industry regulator executives, and five hundred (500) service users. Following a data collection time-frame of seven (7) months, the study employed the use of two research instruments (questionnaires and interviews) while using both stratified and simple random sampling methods. Sequel to the data collection, the quantitative data were analysed using SPSS to conduct a Spearman's rank order correlation coefficient for examining the relationship between the variables and regression analysis for establishing the relationship between variables.

In other to achieve the purpose of the research, the following null hypotheses were tested:

$\mathrm{H}_{1}$ : The new business models do not have any significant influence on HR practices and organisational bottom-lines in the emerging gig economy.

$\mathrm{H}_{2}$ : Diversity and ethical standards do not have any significant effect on organisational bottom- 
lines in the emerging gig economy.

$\mathrm{H}_{3}$ : There is no significant effect of job flexibility on organisational bottom-lines in the emerging gig economy.

\section{Data Analysis}

The data analysis section of this paper is divided into two parts; on the one hand, is the quantitative analysis based on the results derived from the distribution of the questionnaires, while on the other hand is the interview session containing an abridged version of the recordings from the respondents.

\subsection{Hypothesis Testing}

Given the three (3) hypotheses, the Spearman's rank correlation and the regression analysis were adopted. First, Spearman's rho was used to investigate the relationship between the specified variables and used as an indication of the correlation strength. Second, regression analysis was used to determine the degree of relationship between the independent variables and the dependent variable.

\subsubsection{Hypothesis 2: Diversity and ethical standards do not have any significant effect on organisational bottom-lines in the emerging gig economy.}

Table 1: Correlation Coefficient for Diversity and Organizational Bottom-lines

\begin{tabular}{|ll|c|c|}
\hline & & Diversity & Organizational Bottom-lines \\
\hline Diversity & Correlation Coefficient & 1.000 & $.711^{\star *}$ \\
Spearman's rho & Sig. (2-tailed) &. & .000 \\
& $\mathrm{~N}$ & 164 & 164 \\
Organizational Bottom-lines & Correlation Coefficient & $.711^{\star *}$ & 1.000 \\
& Sig. (2-tailed) & .000 &. \\
& $\mathrm{~N}$ & 164 & 164 \\
\hline
\end{tabular}

${ }^{\star *}$. Correlation is significant at 0.01 level (2-tailed).

With a correlation of 0.711 between diversity and organisational bottom-lines, there is evidence of a significant positive relationship between the two variables. Also, given a p-value of $0.000<0.01$, we can reject the null hypothesis. As such, it can be concluded that the relationship between diversity and organisational bottom-lines for Uber and Taxify are statistically significant.

Table 1.1: Coefficients ${ }^{a}$

\begin{tabular}{|l|c|c|c|c|c|}
\hline \multirow{2}{*}{ Model } & \multicolumn{2}{|c|}{ Unstandardized Coefficients } & Standardized Coefficients & \multirow{2}{*}{ T } & Sig. \\
\cline { 2 - 6 } & $\mathrm{B}$ & Std. Error & Beta & & \\
\hline (Constant) & 1.288 & .256 & & 4.763 & .000 \\
1 Diversity & .641 & .071 & .693 & 7.889 & .000 \\
\hline
\end{tabular}

a. Dependent Variable: Organizational Bottom-lines

Given the independent variable (diversity) and the dependent variable (organisational bottom-lines), the regression coefficients reveal a significant relationship between the two variables. The beta value indicates that diversity has a $69.3 \%$ impact on organisational bottom-lines. Also, given a $p-$ value of $0.000<0.05$ level of significance, we can reject the null hypothesis. Thus, the relationship between diversity and organisational bottom-lines for Uber and Taxify are statistically significant. 
Table 2.0: Correlation Coefficient for Ethical Standards and Organizational Bottom-lines

\begin{tabular}{|l|l|c|c|}
\hline & & Ethical Standards & Organizational Bottom-lines \\
\hline Ethical Standards & Correlation Coefficient & 1.000 & $.945^{\star *}$ \\
& Sig. (2-tailed) & .000 \\
Spearman's rho & $\mathrm{N}$ & 586 & 586 \\
& Correlation Coefficient & $.945^{\star *}$ & 1.000 \\
Organizational Bottom-lines & Sig. (2-tailed) & .000 & 586 \\
& $\mathrm{~N}$ & 586 & 586 \\
\hline
\end{tabular}

${ }^{* \star}$. Correlation is significant at 0.01 level (2-tailed).

With a correlation of 0.945 between ethical standards and organisational bottom-lines, there is evidence of a significant positive relationship between the two variables. Also, given a p-value of $0.000<0.01$, we can reject the null hypothesis. As such, it can be concluded that the relationship between the ethical standards and organisational bottom-lines for Uber and Taxify are statistically significant.

Table 2.1: Coefficients ${ }^{a}$

\begin{tabular}{|c|c|c|c|c|c|}
\hline \multirow{2}{*}{ Model } & \multicolumn{2}{|c|}{ Unstandardized Coefficients } & Standardized Coefficients & \multirow{2}{*}{$\mathrm{T}$} & \multirow{2}{*}{ Sig. } \\
\hline & $\mathrm{B}$ & Std. Error & Beta & & \\
\hline $\begin{array}{l}\text { (Constant) } \\
1 \text { Ethical Standards }\end{array}$ & $\begin{array}{l}.009 \\
1.005\end{array}$ & $\begin{array}{l}.073 \\
.027\end{array}$ & .903 & $\begin{array}{c}.121 \\
42.754\end{array}$ & $\begin{array}{l}.904 \\
.000\end{array}$ \\
\hline
\end{tabular}

a. Dependent Variable: Organizational Bottom-lines

Given the independent variable (ethical standards) and the dependent variable (organisational bottom-lines), the regression coefficients reveal a significant relationship between the two variables. The beta value indicates that ethical standards have a substantial impact of $90.3 \%$ on organisational bottom-lines. Also, given a p-value of $0.000<0.05$ level of significance, we can reject the null hypothesis. As such, it can be concluded that the relationship between the ethical standards and organisational bottom-lines for Uber and Taxify are statistically significant.

\subsubsection{Hypothesis 3: There is no significant effect of job flexibility on organisational bottom-lines in the emerging gig economy.}

Table 3.0: Correlation Coefficient for Job flexibility and Organizational Bottom-lines

\begin{tabular}{|l|l|c|c|}
\hline & & Job Flexibility & Organizational Bottom-lines \\
\hline Job Flexibility & Correlation Coefficient & 1.000 & $.821^{* *}$ \\
& Sig. (2-tailed) & .000 \\
Spearman's rho & $\mathrm{N}$ & 164 & 164 \\
Organizational Bottom-lines & Correlation Coefficient & $.821^{* *}$ & 1.000 \\
& Sig. (2-tailed) & .000 &. \\
& $\mathrm{~N}$ & 164 & 164 \\
\hline \multirow{2}{**}{. Correlation is significant at 0.01 level (2-tailed). }
\end{tabular}

With a correlation of 0.821 between job flexibility and organisational bottom-lines, there is evidence of a significant positive relationship between the two variables. Also, given a p-value of $0.000<$ 0.01 , we can reject the null hypothesis. As such, it can be concluded that the relationship between job flexibility and organisational bottom-lines for Uber and Taxify are statistically significant. 
Table 3.1: Coefficients ${ }^{a}$

\begin{tabular}{|l|c|c|c|c|c|}
\hline \multirow{2}{*}{ Model } & \multicolumn{2}{|c|}{ Unstandardized Coefficients } & Standardized Coefficients & \multirow{2}{*}{ T } & \multirow{2}{*}{ Sig. } \\
\cline { 2 - 5 } & $\mathrm{B}$ & Std. Error & Beta & & \\
\hline (Constant) & .006 & .090 & .876 & .115 & .846 \\
1 Job Flexibility & 1.009 & .031 & 38.217 & .000 \\
\hline
\end{tabular}

a. Dependent Variable: Organizational Bottom-lines

Given the independent variable (job flexibility) and the dependent variable (organisational bottomlines), the regression coefficients reveal a significant relationship between the two variables. The beta value indicates that job flexibility has a substantial impact of $87.6 \%$ on organisational bottomlines. Also, given a p-value of $0.000<0.05$ level of significance, we can reject the null hypothesis. As such, it can be concluded that the relationship between job flexibility and organisational bottomlines for Uber and Taxify are statistically significant.

\subsection{Interview Session}

Based on the conducted interviews, data was gathered in order to reject or accept the null hypothesis. The questions were structured towards getting the opinions of the respondents concerning the phenomena in the gig economy.

\subsubsection{Notions of Changes in the Business Model from the Emergence of the Gig Economy}

The respondents comprising the business executives and HR managers in particular and some of the industry regulators were asked to give their opinions on the changing business models in the gig economy. From the responses given, the researchers were able to deduce a common phenomenon that revealed that the gig economy had drastically changed business models. These were some of the recorded views from the respondents:

"Operating in an emerging gig economy like Nigeria has proved to be somewhat challenging based on the fact that although technology is not new to the citizens, some lags need to be filled to encourage tech-businesses to thrive in this environment. The fact that we refer to our drivers or operators as self-employed which has raised many concerns, we still bear the brunt of having to ensure that they are safe in providing the services to our customers. Our business models have been embellished, and just recently, we had to encourage our drivers on the importance of being technologically savvy because, in a few more years, only those with the technological skills and prowess will be able to work with us. The technological world is changing, and we need to move with trends if we must survive; this has caused us as management staffs to go back to the drawing board and start putting things in place." (Business Executive 2).

"As a human resource manager, I can vividly confirm that the way we operate has changed. Prior to gaining entry into Nigeria a few years back, the HR unit has always been tasked with ensuring that our drivers are happy. Moreover, we have always made sure that we give fair treatments to our drivers notwithstanding the challenges that we face as an organisation. It is worthy to note that the $H R$ unit is very concerned about talent acquisition, as we do not only need people who can drive but also those who can take advantage of the technological improvements which we have always been revolved around. We have, therefore, moved from being technologically lenient to being technologically strict, because we want both our drivers and service users to enjoy using our ridesharing apps" (HR Manager 1).

"Having observed the changes that have occurred over the years with the entry of Uber and Taxify, there is no doubt that the Nigerian labour market is composed of various dynamics particularly in the way people choose to work. For the few transportation organisations around, the business models have been unstable because Nigeria is a growing economy still trying to embrace technology and as such, improved technology has changed the thinking of the individual workers and the youth segment in particular. The growth of the gig economy has therefore made it mandatory for organisations to think ahead and implement better strategies for managing the changing patterns of the workforce" (Industry Regulator 1). 


\subsubsection{Notions of the Effect of Diversity and Business Ethics on the performance of the Gig Economy}

The respondents were asked to relay their thoughts on the effects of diversity and business ethics on the performance of the gig economy. The responses given showcased that diversity was a critical challenge for the gig economy, while ethical concerns were at its peak. These were some of the recorded views from the respondents:

"The fact that our drivers are from diverse cultural backgrounds makes it a big challenge for us here in the HR unit to decipher their needs and how to satisfy them on the job sufficiently. Although, it is a requirement that our drivers are literates with at least a first school leaving certificate with a credit in English and Mathematics to help with effective communication; however, some cultural norms impede how they operate at times. For instance, a few of them are impatient and sometimes become rude to customers; and it is our culture that if a customer speaks rudely, the driver should remain calm. Also, we encourage our drivers to maintain high ethical standards and desist from being found wanting, and we have been able to monitor this through the surveys and rating initiative on our app" (HR Manager 2).

"It is important to state that as a driver, I am aware of the difference in cultural beliefs and for many of us, we are only humans, and there is the tendency that these differences separate us from each other. The fact that we come from different cultures where thinking and behaviour are slightly or more different from the other, there are bound to be challenges and problems. For some of us, we feel happy when our customers share the same belief, and over time it has been more productive as riding becomes more interesting. Nonetheless, we are not oblivious of the ethical concerns during the discharge of our service, but we are more concerned with the organisation we work for being unfair in some ways particularly regarding our labour rights" (Operator 2).

"Without any doubt, just like in many other industries there are quite some shortcomings when it comes to diversity and ethical standards. In this industry, many of the challenges have been particularly about the unethical practices of the concerned organisations. The major concerns have been the complaints about low pay and high commission, cut in service charge without a corresponding reduction in the commission charged by some of the transport companies, job insecurity, disregard for labour rights, and fraudulent activities among the drivers who connive with customers to go offline in pretence of a cancelled trip. These and many more have been a result of the diversity in the workforce and have raised many concerns for the gig economy" (Industry Regulator 2).

\subsubsection{Notions of the Effect of Job Flexibility on the performance of the Gig Economy}

The respondents were asked to relay their thoughts on the effects of job flexibility on the performance of the gig economy. The responses given butressed that job flexibility served as a primary tenet of the gig economy. These were some of the recorded views from the respondents:

"The HR unit is aware of the outcry of our drivers for increasing job flexibility, and so we are not in any way contesting that they remain glued to offering other services as long as it is not with our direct competitors. It does not speak well of them even if we regard them as being self-employed to offer a service to our competitors and even though we are aware of a few, we have been lenient and trying to encourage them to desist from such unethical acts. Nevertheless, our drivers are free to work in other organisations that are outside our scope in order to derive more income." (HR Manager 1).

"The situation of the country warrants that we can juggle between jobs and to do this, our primary workplace needs to ensure work flexibility and respect our decisions to decline any ride as long as it has been duly reported. Many a time, we could be taken off the active list after three consecutive declines, which are mostly because of our commitment to another job to earn a better living since they are unable to increase our pay. In addition, we are being deprived of our labour rights, and this has led to many fraudulent acts among colleagues, not because they wish to but probably because of the lack of job satisfaction. So, if we decide to work part-time, let our decisions be respected" (Operator 2).

"Because of the large number of drivers/colleagues, there are some very slow business times where for a week I might not have more than three rides; however, the organisation expects us to be readily available which in reality, in this line of work is unrealistic particularly because we have families to feed. We, therefore, need some job flexibility to enable us to work with other 
organisations to boost our income. We also want the organisation to recognise our rights and pay us more than we currently earn and also make us entitled to paid leaves alongside a stable working condition. One critical need is for the organisation to increase the standard of security by ensuring that the riders have been adequately verified to reduce the risk of passengers killing the drivers which are still recent news in the industry" (Operator 3).

\section{Discussion of Findings}

In a bid to investigate the impact of the new business models on HR practices and organisational bottom-lines, the researchers were able to gather some information from the interviews conducted with the disruptive and innovative (D\&l) business executives and industry regulators. The prevalent themes identified included technology, talent acquisition and increased labour protection. The respondents alluded that the continuous changes in technology is a significant determinant for business survival and as such, the drivers are encouraged to get familiarised with improved technology or risk losing their jobs. In addition, there is a high need for talent/skill-based workers to stimulate growth in the industry and the organisations in particular as it serves as a medium of achieving competitive advantage (Balaram et al., 2017). Also, the transport platform organisations are intensifying efforts towards improving the safety of their drivers; this has led to the need for additional verification of riders. Therefore, it is safe to conclude that the new business models are beginning to change the direction of HR practices and influence business performance (Bracha and Burke, 2018).

The findings from the effect of diversity and ethical standards have proved to be significant. Results, from the quantitative analysis conducted, reveal that diversity had a significant effect on organisational bottom-lines, while ethical standards had a stronger influence on organisational bottom-lines. In triangulating this result, the recordings from the interviews supported the results from the quantitative analysis. The major themes identified include the differences in culture which was adjudged to play a significant role in the business-worker relationship and driver-service-user relationship. This is in line with the findings of Anita and Swamy (2018) in which they espouse the intrigues of workplace diversity. It revealed that there are a few detrimental effects of cultural diversity on the smooth running of the business stemming from the fact that individuals from different cultural backgrounds tend to elicit different behaviours and attitudes. Also, the biggest issue was to deal with the strong effect of ethical standards. The dominant themes from the analysis included unfair treatment by the transport organisations of the employees in terms of respecting their labour rights. Many of the complaints given bothers on a low income, high commission, service charge cut, job insecurity to mention a few. The businesses executives also complained about the fraudulent acts displayed by their drivers to short-change them from getting their commission from completed rides. However, the organisations reportedly confirmed their efforts towards ensuring that the bar of ethical standards is at a high level. Such position was corroborated in the work of Mcdonnell et al. (2018)

In the examination on the effect of job flexibility on organisational bottom-lines, it was revealed from the quantitative analysis that there is a significant effect of job flexibility on business performance. Interviews conducted further confirmed this as it revealed the influence of job flexibility on employee job satisfaction and the ability to be more committed to the goals of the organisation in line with the works of Mordi (2008) and Ajonbadi (2016). The most prevalent theme is the need to work multiple jobs geared towards improving the income support of the workers. The drivers during interview asserted that they felt unfairly treated as they were rarely able to take on other jobs based on the requirement of their employers to be readily available for work. They opined that they would be happier if the transport organisations were able to give some form of job security or grant them less working hours to enable them to do other jobs. However, the HR departments are only being careful not to allow their drivers to offer services to their direct competitors which would hamper the growth of their organisations. 


\section{Conclusion and Recommendations}

From the findings and discussions provided thus far in this paper, it is safe to conclude that disruptive and innovative new business models, mostly technology driven, have changed the thinking of contemporary HR and without any doubt, there are implications on organisational bottom-lines. Also, the influence of diversity on the operations in the public transportation platform as understudied cannot be underestimated. It has been proven that differences in cultural backgrounds, in particular, affect the relationship between the three principal parties that is, the business, service operators/drivers and service users. More importantly, is the significance of ethical standards on the growth of the industry. Despite the potentials for growth, ethical concerns been at its peak may impede the rapid growth of the industry. Additionally, flexi-working has a significant impact on organisational bottom-lines as workers are only motivated to be committed where there is job satisfaction and increase in income.

Nonetheless, it is essential for the organisations within the industry to consider the need for ensuring fairness to all employees, eradicating tribal, age, gender and income discrimination, ensuring that the role of technology does not encroach into the privacy and flexibility of employees but rather to enhance their skills, development and overall competence. Also, HR managers must be able to understand their workforce and make their organisation's policies and practices clearer and transparent to enhance performance. Importantly, HR professionals need to implement new initiatives that tilt more toward talent portfolio acquisition and on-demand recruitment services. As such, HR professionals are expected to be able to anticipate change, generate confidence among their workers, initiate actions, liberate thinking and evaluate results.

\section{References}

Adekoya, O., Olawoyin, F., Olajide, M., \& Bamikole, S. (2018). Global outsourcing relationships: testing the effects of culture and market pressures on outsourcing performance. A case study of Yahweh God's Will Limited, Nigeria. Scholars Journal of Economics, Business and Management, 5(10): 928-940.

Adeleke, D. (2017). As the gig economy slowly grows in Nigeria, who gets the short end of the stick? [blog] Ventures Africa, 16 May. Available at: http://venturesafrica.com/this-tech-start-up-is-revolutionising-theproperty-business/

African Business Central (2017). Uber and its rivals are struggling to keep both drivers and riders happy in Lagos. [online] African Business Central, 25 May. Available at: https://www.africanbusinesscentral.com/2017/05/25/uber-and-its-rivals-are-struggling-to-keep-bothdrivers-and-riders-happy-in-lagos/

Ajonbadi, H.A. (2016), Rhetorics of Labour Contracting as a Managerial Tool among Multinational Oil Corporations in Nigeria. Innovative Journal of Business and Management, India, Vol. 18(4), December.

Anita, R., \& Swamy, V.K. (2018). Diversity Management at Workplace: Aspects, Challenges, and Strategies. International Journal of Engineering Technology Science and Research, 5(1), 306-316.

Anjorin, R.A., \& Jansari, A. (2018). Managing Cultural Diversity at Workplace. Bachelor Thesis, Jonkoping University [online] Available at https://www.diva-portal.org/smash/get/diva2:1217258/FULLTEXT01.pdf

Balaram, B., Warden, J. \& Wallace-Stephens, F. (2017). Good gigs - a fairer future for the UK gig economy. [online] Available at: https://www.thersa.org/globalassets/pdfs/reports-/rsa_good-gigs-fairer-gig-economyreport.pdf

Bracha, A., \& Burke, M. (2018). The ups and downs of the gig economy, 2015-2017. Working Papers, Federal Reserve Bank of Boston, No. 18-12.

Butler, S. (2018). Uber loses appeal over driver employment rights. [blog] The Guardian, 20 December. Available at: https://www.theguardian.com/technology/2018/dec/19/uber-loses-appeal-over-driveremployment-rights

Chander, T. (2017). Gig" economy business model is on the rise. [online] Available at: https://www.wrighthassall.co.uk/knowledge/legal-articles/2017/08/24/gig-economy-business-model-rise/

Darwin, J.R., \& Palanisamy, C.S. (2015). The effects of workforce diversity on employee performance in Singapore organisations. International Journal of Business Administration, 6(2), 17-29.

Daud, N. (2017). Job security and well-being among private workers in Malaysia. Journal of Technology Management and Business, 4(1), 25-38.

Delgado, M. (2018). How the gig economy affects the workplace in 2018. [online] Available at: https://clutch.co/hr/resources/how-gig-economy-affects-workplace-2018 
Deloitte Millennial Survey (2018). Millennials disappointed in business, unprepared for industry 4.0. [online] Deloitte. Available at: https://www2.deloitte.com/content/dam/-Deloitte/at/Documents/human-capital/atdeloitte-millennial-survey-2018.pdf

Gallup (2018). The gig economy and alternative work arrangements. [online] Available at: https://www.gallup.com/file/workplace/240878/Gig_Economy_Paper_2018.pdf

Harris, B. (2017). Uber, Lyft, and regulating the sharing economy. Seattle University Law Review, 41 (1), 269 285.

Horney, N. (2018). The gig economy: A disruptor requiring HR agility. The Professional Journal of HR People + Strategy, 39(3), 20-27.

Khaleej Times (2018). Now, do multiple UAE jobs without employer's consent. [online] Khaleej Times, 20 March. Available at: https://www.khaleejtimes.com/news/general/uae-companies-can-now-hireemployees-under-part-time-contract

Kshetri N. (2007). Institutional factors affecting offshore business process and information technology outsourcing. Journal of İnternational Management, 13, 38-56.

Mcdonnell, A., Burgess, J., Carbery, R., \& Sherman, U. (2018). Gig work: implications for the employment relationship and human resource management. The International Journal of Human Resource Management. Special Issue, 1-4. 10.1080/09585192.2018.1495410.

Michelle, T. \& Helen, L. (2016). Improving worker's health in project-based work: job security considerations. International Journal of Managing Projects in Business, 9(3):606-623.

Mojeed-Sanni, B. A. \& Adetunji, A. T. (2015), Recruitment and selection process: elements of organisational social capital building - A study of Nigerian Medium Enterprises Human Resource Practitioners. International Journal of Research in Economics and Social sciences, 5(9): 50-61.

Mordi, C. (2008), Segmented work and ethnic divided workers in the Nigerian oil sector. International Africa Academy of Business and Development Journal. 4(2), 24 -38.

Nwanze, C. (2017). The emerging gig economy in Nigeria. [blog] Financial Nigeria, 12 July. Available at: http://www.financialnigeria.com/the-emerging-gig-economy-in-nigeria-blog-267.html

Rao, S. (2016). How Uber is monitoring its drivers. [blog] News.com.au. Available at: https://www.news.com.au/finance/business/travel/how-uber-is-monitoring-its-drivers/newsstory/e1e1189b49f4da026907cb8aee9d3c05

Saunders, M., Lewis, P. \& Thornhill, A. (2016). Research methods for business students. Harlow: Pearson Education Limited.

Sharpe, S. (2015). Intuit forecast: 7.6 million people in on-demand economy by 2020. Intuit Inc. Available at: http://investors.intuit.com/Press-Releases/Press-Release-Details/2015-/Intuit-Forecast76-Million-Peoplein-On-Demand-Economy-by-2020/default.aspx.

Staffing Industry Analysts (2018). The human cloud, the gig economy \& the transformation of work. [online] Available at: https://www2.staffingindustry.com/site/content/download-/266526/9732110/2018 _GigEconomy_Summary_Web_1810.pdf

Ugargol, J. D., \& Patrick, H. A., (2018). The relationship of workplace flexibility to employee engagement among information technology employees in India. South Asian Journal of Human Resources Management, 5(1), 40-55.

Vanguard (2018). Uber monthly passenger base in Nigeria hits 267,000. [online] Vanguard News, 15 August. Available at: https://www.vanguardngr.com/2018/08/uber-monthly-passenger-base-in-nigeria-hits-267000/

Vercida (2017). The gig economy and diversity \& inclusion. [blog] Vercida. Available at: https://www.vercida.com/uk/articles/vercida-the-gig-economy-and-diversity-inclusion

World Economic Forum (2018). The future of job reports 2018. [online] Available at: http://www3.weforum.org/docs/WEF_Future_of_Jobs_2018.pdf 